\title{
Eticidad Sustancial y Discurso. Hegel en la fundamentación de la ética de Karl-Otto Apel
}

\section{Substantial ethical aspect and speech. Hegel in the grounding of Karl Otto Apel's ethics}

Dr. Leandro Paolicchi

\begin{abstract}
Resumen
El presente trabajo tiene como objetivo detectar cuáles son aquellos elementos del pensamiento de Hegel que la ética del discurso de Karl-Otto Apel ha incluido en su configuración. Para ello se repasan brevemente algunas falencias en la filosofía práctica de Kant, tal como son detectadas por Apel y algunos de sus discípulos, con el objetivo de resaltar los aportes del pensamiento hegeliano a la fundamentación de la ética discursiva. Finalmente se señalan también en este artículo cuáles son los aspectos del pensamiento hegeliano explícitamente criticados por Apel y a los cuales no hace lugar dentro de su programa normativo.
\end{abstract}

Palabras clave: Ética - Fundamentación - Karl-Otto Apel - Discurso Hegel - Eticidad

\begin{abstract}
:
The present work has as a target to find out some elements of Hegel's thinking that the ethics of Karl-Otto Apel's speech has included in its own configuration. For this purpose, some deficiencies in the practical philosophy of Kant are briefly reviewed, as they are detected by Apel and some of his disciples, with the aim of underline the contributions of Hegel's thinking to the grounding of discursive ethics. Finally, this article mentions which aspects of Hegel's thinking are explicitly criticized by Apel and which are not included within its normative program.
\end{abstract}

Key words: Ethics - Grounding - Karl-Otto Apel - Speech - Hegel Ethical aspect 


\section{Introducción}

La filosofía práctica de Kant ha quedado en la historia de la filosofía como uno de los intentos más sólidos y consistentes de fundar la autonomía de la moral a partir de la capacidad del hombre de autodeterminarse a través de la razón. Este intento de fundamentación representó en su momento una ruptura radical con la forma en que se venía entendiendo la conformación de la razón práctica'. Eliminando sus compromisos metafísicos, los continuadores contemporáneos de una razón práctica al estilo kantiano, especialmente Karl-Otto Apel, han procurado retener la idea de una fundamentación de normas éticas a partir de un a priori de la razón, pero no ya teniendo como base la razón subjetiva moderna de Kant, sino una razón plural que puede reconstruirse desde la dimensión argumentativa del lenguaje².

Ahora bien, junto con la intención de resguardar el núcleo duro del kantismo ético, los representantes actuales de esta corriente de pensamiento se vieron confrontados con la necesidad de hacer lugar a una serie de críticas que mostraban inconsistencias reales dentro del antiguo planteo de Kant ${ }^{3}$. Algunas de las críticas que recibieron esta consideración fueron ya en parte también planteadas por Hegel y continuadas por una serie de pensadores a lo largo del siglo XIX. Es aquí donde propiamente este trabajo encuentra su lugar, pues lo que aquí se procurará hacer es rastrear los aportes que estas críticas de Hegel a la filosofía de Kant pueden dar al problema de la fundamentación de normas, desde la perspectiva de la fundamentación pragmático-trascendental de la ética hecha por Karl-Otto Apel. Más

1 KUHLMANN, W., "Solipsismus in Kants Praktische Philosophie", en Apel, K.-O. \& Pozzo, R. Zur Rekonstruktion der praktischen Philosophie, FroomannHolzboog, Stuttgart-Bad Canstatt, 1990, p. 246.

2 Id., "Transzendentalphilosophie nach dem linguistic turn", en Id. Kant und die Transzendentalpragamtik, Königshausen \& Neumann, Würzburg, 1992, pp. 22 y 27 passim.

3 HABERMAS, J., "Treffen Hegels Einwände gegen Kant auch auf die Diskursethik zu?" en Id. Erläuterungen zur Diskursethik, Suhrkamp, Frankfurt a. M., 1991, pp. 9 - 30. 
precisamente, el trabajo rastreará de qué manera y en qué medida la fundamentación de una ética universal emprendida por Karl-Otto Apel sobre el trasfondo de una pragmática trascendental del lenguaje tiene en cuenta o incluye las críticas de la filosofía hegeliana a la filosofía práctica de Kant. Para ello el presente artículo se divide en dos partes: (I) por un lado, se rescatan aquellos elementos de la crítica de Hegel a Kant que para Apel deben ser necesariamente tenidos en cuenta para una consideración normativa de las acciones de los hombres. En este sentido, se repasan dentro de esta primera parte las limitaciones del planteo práctico kantiano, en especial el referido a la consideración de las acciones humanas desde la óptica del dualismo metafísico que afecta a todo su desarrollo. El dejar a la luz las falencias del planteo práctico kantiano tendrá como objetivo resaltar el aporte representado por la tematización del ámbito de la eticidad por parte de Hegel que "descubre" un conjunto de fenómenos ignorados en los ámbitos tradicionalmente tratados por Kant: la moralidad y el derecho.

Una vez desarrollada esta primera parte se abordará en una segunda (II) el intento propiamente hegeliano de superar el dualismo entre teoría y praxis con el desarrollo de una "captación de la realidad" de la eticidad substancial y qué indicaciones normativas es posible extraer desde este punto de vista. A partir de aquí se buscará reconstruir las críticas de Apel a la idea hegeliana de reemplazar el bosquejo clásico de la razón práctica, es decir, los planteos clásicos de tipo ético-político normativos, por una filosofía teórica que intenta comprender la historia como una realización progresiva de la razón y la libertad.

\section{La Necesidad de una consideración del planteo de Hegel de una eticidad sustancial}

\section{1 Kant y la comprensión en clave conductista de las acciones humanas}

Uno de los puntos fundamentales en donde Hegel asentó sus críticas más agudas a Kant fue en un aspecto que atraviesa todo el planteo 
del filósofo de Königsberg y que Hegel vio como un rasgo típico de la razón moderna. Hegel hizo foco desde un principio en el dualismo que caracteriza tanto a la filosofía teórica como a la filosofía práctica de Kant. Así como las consideraciones gnoseológicas de Kant están atravesadas por la distinción entre un mundo de fenómenos y un mundo de noúmenos, la misma distinción vertebra su filosofía práctica: en este caso corresponde hablar de los dos mundos que habita el hombre en tanto poseedor de un cuerpo, y por tanto de inclinaciones, y de una razón. Ambas instancias definen respectivamente un yo empírico y un yo inteligible ${ }^{4}$.

Esta distinción tan fundamental a todo el pensamiento de Kant fue necesaria en virtud de los compromisos teóricos contraídos previamente por Kant y que permanecen sin ser evaluados críticamente en su totalidad. Esta distinción está pensada en Kant como una forma de salvar el problema de la libertad que se había convertido en problemático, al adoptar Kant un concepto de experiencia que proviene esencialmente de las ciencias naturales y en el cual tiene un papel fundamental el esquema de la causalidad, transformado en Kant en un esquema trascendental ${ }^{5}$. En verdad, el concepto de experiencia es uno de los aspectos más problemáticos de la filosofía trascendental kantiana y que lo enfrenta claramente a las aporías del paradigma de la filosofía de la subjetividad centrado en el objetivismo y en el solipsismo de la conciencia ${ }^{6}$. La trascendentalización del esquema de

4 KANT, I., Grundlegung zur Metaphisik der Sitten en Id., Kants gesammelte Schriften, Akademie-Textausgabe, Bd. IV, De Gruyter, Berlin, 1968, p. 452.

5 Id., Kritik der reinen Vernunft en Id., Kants gesammelte Schriften, ed. cit., Bd. III, pp. 64, 89 y 207.

6 Para una consideración más detallada del concepto de experiencia en Kant y los problemas que éste trae consigo cf. BÖHLER D., Rekonstruktive Pragmatik. Von der Bewußtseinsphilosophie zur Kommunikationsreflexion: Neubegründung der praktischen Wissenschaften und Philosophie, Suhrkamp, Frankfurt a.M, 1985, pp. 33-47 y KUHLMANN, W., "Transzendentalphilosophie nach dem linguistic turn", ed. cit., pp. 68 - 69. Allí, Kuhlmann desarrolla la idea de que la experiencia está en Kant irreflexivamente concebida pues falta allí crítica y discusión de conceptos fundamentales, intereses y perspectivas, p. 68. En suma, para Kuhlmann, Kant trabaja con un concepto acotado e insuficiente de experiencia, p. 69. 
la causalidad amenazaba a todo el planteo de Kant con la sombra de un determinismo que cercena de cuajo toda posibilidad de un actuar moral en el hombre. De aquí que Kant se vea obligado a considerar una causalidad de la libertad como una forma de salvar la espontaneidad de la razón (autónoma) que aplica sus conceptos al caos de la experiencia sensible y que le permite al hombre considerar con sentido la posibilidad de un actuar moral, en la medida en que se considera a la libertad como una fuente de la acción.?

La libertad en este planteo queda remitida invariablemente a un mundo inteligible, en el que no puede ser conocida, pero que debe ser necesariamente pensada como una facultad posible del yo en tanto participa de este mundo. Este "yo inteligible" en la medida en que participa de ese mundo inteligible, y por lo tanto puede actuar libremente, permanece separado de este mundo experimentable y conocible de la experiencia sensible ${ }^{8}$.

La consecuencia altamente relevante en términos éticos que tiene esta división entre dos mundos, en la cual la libertad aparece relegada a un reino inteligible que puede ser pensado pero no conocido, es que los hechos morales, y en general todos los actos libres de las personas, no pueden ser conocidos empíricamente. Aun más, no sólo los actos de los individuos no pueden ser reconocidos como tales, es decir, como acciones de individuos, sino que los otros "yoes" no pueden ser conocidos tampoco empíricamente9. En otros términos, no se puede acceder cognoscitivamente con los parámetros kantianos a la interioridad de los otros individuos y, por lo tanto, no se puede conocer su status como personas que actúan voluntariamente y con un sentido determinado. Nos encontramos aquí con el característico

7 BÖHLER D., Rekonstruktive Pragmatik, ed. cit., p. 55; KANT, I., Kritik der praktischen Vernunft en Id., Kants gesammelte Schriften, ed. cit., Bd. V, pp. 56 y 110 y Grundlegung zur Metaphisik der Sitten en Id., Kants gesammelte Schriften, ed. cit., Bd. IV, pp. 4, 417 y 451.

8 BÖHLER D., Rekonstruktive Pragmatik, ed. cit., p. 55

9 KUHLMANN, W., "Solipsismus in Kants Praktische Philosophie", ed. cit., pp. 262; BÖHLER D., Rekonstruktive Pragmatik, ed. cit., p. 57 y 58. 
y problemático -sobre todo si nos estamos refiriendo principalmente a cuestiones prácticas- solipsismo moderno de la conciencia al que Kant no sólo no pudo escapar sino al que dio rango trascendental. A partir de un punto de partida como el adoptado por Kant, y al que en parte se vio obligado a adoptar para salvar el problema de la libertad al que se vio arrastrado por aceptar él mismo un concepto de experiencia tomado de las ciencias naturales, las acciones no pueden ser sino ya comprendidas de un modo conductista. Es decir, las acciones de los hombres deben ser concebidas como movimientos "exteriores" que responden a estímulos también exteriores, pero nunca como acciones libres de individuos dotados de razón que dan sentido a sus acciones ${ }^{10}$.

Con esta decisión Kant aleja del mundo cognoscible de los fenómenos todo el ámbito de la interioridad de los hombres -al menos el de los otros hombres-, precisamente, aquel en donde aparece implicada en primer término la moralidad. En este sentido, con el umbral de cognoscibilidad que Kant determina en Kritik de reinen Vernunft, se le presenta a éste la dificultad de determinar cuándo alguien efectivamente actúa por criterios morales o simplemente se deja conducir de acuerdo a los patrones de la legalidad, de acuerdo a la distinción trazada por Kant en torno a un actuar por deber (moralidad) o simplemente de acuerdo a éste (legalidad). Como señala Apel ${ }^{11}$, de aquí se desprende la posibilidad, ciertamente inquietante, de que posiblemente el comportamiento de los hombres nunca esté motivado por la ley moral. Pero, como también acertadamente agrega, esto se contradice con el sentido de una exigencia del deber. Pues qué sentido puede tener una exigencia de tipo moral si no podemos saber cuándo actuamos moralmente y cuándo no ${ }^{12}$. En verdad, debe decirse que en general el destino de la razón práctica kantiana está trazado en Kritik der reinen Vernunft y en el concepto de razón que allí se desarrolla. La razón

\footnotetext{
10 BÖHLER D., Rekonstruktive Pragmatik, ed. cit., p. 57.

11 APEL, K.-O. Diskurs und Verantwortung. Das Problem des Übergangs zur postkonventionellen Moral, Suhrkamp, Frankfurt, 1988, p. 78.

12 Loc. cit.
} 
kantiana está tan claramente delineada dentro del marco del solipsismo y el objetivismo de la filosofía moderna, es decir, desarrollada como una facultad para la explicación de la constitución del mundo de la experiencia que difícilmente puede hacer plausible la idea de una razón práctica ${ }^{13}$.

A esta altura está bien claro que Kant maneja un concepto de experiencia -el de las ciencias naturales- que deja afuera todo un conjunto de fenómenos que sólo serán rescatados de las sombras por todo el pensamiento que se desarrollará a fines del siglo XVIII y principios del XIX y que formarán parte del ámbito de estudio de las ciencias del espíritu (Geisteswissenchaften) y, en el siglo XX, también de la sociología comprensiva que va desde Weber a Habermas. Es decir, el pensamiento posterior a Kant no solo sacará a la luz la dimensión de la historia que estaba ausente en su concepción de la razón subjetiva y en su concepto de experiencia ${ }^{14}$ sino, de un modo más fundamental, aquello que el objetivismo de Kant había hecho desaparecer, a saber, el ámbito pleno de sentido del actuar y del comprender de los hombres en el mundo de la vida constituido históricamente ${ }^{15}$. Quien primero hizo esto posible, gracias al descubrimiento de un amplio ámbito que no se encuentra ni en la interioridad inasequible en términos de conocimiento ni en la exterioridad accesible en términos de la experiencia, fue Hegel ${ }^{16}$. En gran medida, esto puede hacerlo Hegel gracias al desarrollo de una tercera instancia que se ubica junto a las instancias tradicionalmente descritas por Kant, es decir, junto a la moralidad y el derecho. Hegel denominó a este tercer ámbito "Sittlichkeit" que tradicionalmente se traduce por moralidad, pero al existir ya un uso de este término y al

\footnotetext{
13 KUHLMANN, W., "Transzendentalphilosophie nach dem linguistic turn", ed. cit., p. 22.

14 KUHLMANN, W., "Was spricht heute für eine Philosophie des kantischen Typs?" en Id. Kant und die Transzendentalpragamtik, Königshausen \& Neumann, Würzburg, 1992, p. 69.

15 BÖHLER D., Rekonstruktive Pragmatik, ed. cit., p. 68.

16 APEL, K.-. "Ist die Philosophische Letzbegründung moralischer Normen auf die reale Praxis anwendbar?" en Apel, K.-O., Böhler, D. und Rebel, K. (Hrgs.). Studientexte 2 Funkkolleg Praktische Philosophie / Ethik, Beltz, Weinheim und Basel, 1984, p. 615.
} 
querer Hegel diferenciar explícitamente a la Sittlichkeit de la Moralität se la tradujo como "Eticidad". A continuación desarrollaré en líneas generales este concepto tal como está expuesto por Hegel en los Grundlinien der Philosophie des Rechts y como éste sirve para dejar al descubierto ese conjunto de fenómenos que fueron pasados por alto por el planteo kantiano.

\section{2 El Concepto de Eticidad en los Grundlinien der Philosophie des Rechts de G. W. F. Hegel}

La importancia del concepto de Eticidad en Hegel reside, como se dijo, en que éste permite la caracterización de un conjunto de fenómenos que habían quedado fuera de consideración en el planteo kantiano en virtud del concepto de experiencia con el que éste se manejaba. En primera instancia Hegel se refiere con el concepto de eticidad a un conjunto de fenómenos experimentables y que pueden ser comprendidos o conocidos como producto de una moral realizada. Se trata de un conjunto de principios, de prácticas y agentes moralmente desarrollados ${ }^{17}$. Es decir, la eticidad no se agota de ninguna manera en una interioridad de los individuos inasequible para el conocimiento sino que más bien su principal característica consiste en la exteriorización y permanencia de un mundo: "Es el concepto de la libertad que ha devenido mundo existente y naturaleza de la autoconciencia" (§142) o "De este modo lo ético tiene un contenido fijo que es por sí necesario y una existencia que se eleva por encima de la opinión subjetiva y del capricho: las instituciones y leyes existentes en y por si" (\$144). De fundamental importancia es aquello que menciona en $\S 147$ y que sirve para diferenciar a este tipo de fenómenos de los fenómenos naturales:

Por otra parte, estas leyes éticas no son para el sujeto algo extraño, sino que en ellas aparece, como en su propia esen-

17 WESTPHAL, K., "The basic context and structure of Hegel's Philosophy of Right" en Beiser, F. (ed.). The Cambridge Companion to Hegel, Cambridge University Press, Cambridge, 1993, p. 254. 
cia, el testimonio del espíritu. Allí tiene su orgullo y vive en su elemento, que no se diferencia de sí mismo. Es una relación inmediata, aun más idéntica que la de la fe y la confianza." (Las cursivas son de Hegel)

A partir de aquí son muchos los parágrafos en donde Hegel destaca una y otra vez aquello que diferencia a la eticidad de la moral y el derecho y donde queda determinado una y otra vez el carácter real y espiritual que vertebra a este concepto y no la abstracción que caracteriza a las otras instancias. Por ejemplo en $\S 151$ y en su agregado donde lo ético aparece bajo la forma de la costumbre. Un aspecto fundamental que debe quedar aquí en claro a la luz de las relaciones que se establecen entre la eticidad, la moralidad y el derecho es que la posibilidad de realización de los dos últimos depende enteramente de la realidad de la eticidad ( $\$ 141$ ). La forma en que Hegel introduce la eticidad, luego del derecho y la moralidad, no debe hacer perder de vista el carácter retroactivo del análisis hegeliano y, por lo tanto, el carácter de fundamento, de verdad, de aquello que se presenta en última instancia. Es decir, las condiciones de posibilidad del derecho abstracto y la moralidad no se encuentran en ellas mismas sino en la eticidad ${ }^{18}$. Es esencial a los fines de este trabajo tener presente que la eticidad abarca no solo una interioridad que conoce o acepta determinadas normas sino también la validez objetiva de un conjunto de normas, leyes e instituciones.

Ahora bien, la eticidad tal como está presentada en Grundlinien der Philosophie des Rechts se divide en tres partes: la familia, la sociedad civil y el Estado (\$157). La familia tiene en relación con la educación, según Hegel, una determinación positiva y una negativa: la positiva consiste en "llevar la eticidad de la sensación inmediata y aún no contrapuesta, para que el alma viva la primera parte de su vida teniendo al amor, la confianza y la obediencia como fundamento de la vida ética" y la negativa "elevar a los niños de la inmediatez natural en que

18 Ibíd., p. 255. 
originariamente se encuentran a la independencia y a la libre personalidad, y con ello a la capacidad de abandonar la unidad natural de la familia" (\$175). Es decir, en la familia el espíritu ético se presenta en su total inmediatez y naturalidad determinando a aquella a través del amor como una unidad sentida, que se pierde luego, en el segundo momento, dando lugar a la sociedad civil.

El análisis de la sociedad civil resulta de particular importancia aquí, pues es la instancia que Kant tiene ante sus ojos y la que le dificulta la conceptualización de los fenómenos que la eticidad pone en juego. Kant se "queda" en la sociedad civil como el propio estado de la sociedad. La sociedad civil, para Hegel, está caracterizada por ser una unión de individuos particulares que se unen a través de un derecho formal, una constitución jurídica, para su seguridad y la protección de su propiedad privada. Asimismo, la sociedad civil se conceptualiza como una esfera que comprende, como una parte fundamental de su ámbito, a la moderna economía de mercado y, en este sentido, comprende lo que Hegel denomina "sistema de las necesidades" (\$188), es decir, un sistema organizado en torno a la "producción, distribución y consumo de productos que satisfacen una variedad de necesidades y deseos ${ }^{\prime 19}$. Por último, la sociedad civil abarca otro conjunto de instituciones como la policía (Polizei) y la corporación (§188). Lo fundamental aquí es que este estado, al que Hegel llama "estado exterior" $(\$ 183)^{20}$, debe necesariamente resolverse en una tercera instancia en la cual tiene lugar la síntesis entre la libertad subjetiva y la sustancia ética ya plenamente autoconciente. Esta síntesis, se produce ni más ni menos que en el ámbito del Estado el cual lleva a su plena realización la idea de lo ético (§ 257).

Lo importante aquí, en función de determinar cuáles son los aspectos que Apel rescata de las críticas de Hegel a Kant, es que Apel ve un

\footnotetext{
19 lbíd., p. 257.

20 Hegel lo llama así pues este estado es concebido esencialmente como un medio para la consecución de fines personales y porque no se alcanza aquí la autonomía política. Véase al respecto Westphal, op. cit., p. 239.
} 
aporte fundamental en la conceptualización de lo ético. Apel acuerda en este punto con Hegel en que en los ámbitos de la economía y el derecho, dentro de la sociedad civil, está ausente una dimensión de la eticidad y que es, en palabras de Apel, "la posibilidad de una identificación moral de los individuos con una comunidad en el sentido de la solidaridad"21. Aquí Apel habla de una identificación moral para referirse, como Hegel, a un tipo de fenómeno que se produce entre los sujetos de una comunidad y su Estado y que solo puede provenir de la interioridad de estos sujetos, pero a la que debe corresponder la validez objetiva de las leyes, las instituciones y el Estado.

Esta era precisamente una de las faltas que Apel creía ver en la propuesta kantiana de acuerdo a la cual, en el ámbito del derecho no se puede exigir que los hombres actúen por deber, sino que debe uno conformarse, para que un Estado funcione, en que éstos se comporten externamente de acuerdo a él. Para Apel esto último puede ser cierto, pero ello no implica de ningún modo que un estado de derecho pueda funcionar si los individuos que lo componen actúan siempre y exclusivamente de acuerdo a imperativos egoístas de éxito personal, como en la sociedad civil descrita por Hegel, y nunca actúan por deber, como lo prescribiría el imperativo categórico, es decir, de acuerdo a algún tipo de intención moral ${ }^{22}$. Si esto no sucediera sería posible pensar un Estado de derecho cuyas obligaciones legales fueran aceptadas y justificadas sin una legitimación moral, sino sólo por motivos egoístas. Aquí Kant solo concedería que debe haber necesariamente una legitimación moral del Estado de derecho y que esta proviene de la idea a priori de contrato. Sin embargo, también afirmaría que el funcionamiento de un Estado es perfectamente posible sin ningún tipo de identificación moral entre los individuos y su Estado, cosa que, como se vio, para Hegel es perfectamente imposible. Parecería estar fuera del horizonte kantiano aquel fenómeno que Hegel se esfuerza por traer a concepto y que Apel ve como un verdadero logro de este último:

APEL, K.-O., Diskurs und Verantwortung, ed. cit., p. 83.

22 Ibíd., p. 75. 
la unidad (ética) que se produce en el individuo con su comunidad y que puede testimoniarse en el fenómeno de la solidaridad. La imposibilidad kantiana de captar este tipo de fenómeno puede de alguna manera entenderse como la imposibilidad primigenia de acceder cognoscitivamente desde las propias premisas del planteo kantiano a la interioridad de los otros.

Sin embargo, una vez que Apel ha rescatado este elemento fundamental conceptualizado por Hegel y que sirve como compensación de un déficit profundo que aquejaba al planteo kantiano en la descripción de la praxis social de los hombres, comienza a señalar sus limitaciones. A partir de aquí Apel criticará aquello que Hegel describe como aconteciendo en el seno del Estado, es decir, la realización efectiva de la idea ética, la revelación del espíritu como voluntad sustancial ( $§$ 257), el momento de la mediación total de la libertad subjetiva y la libertad objetiva. Las primeras limitaciones de la formulación hegeliana saltarán a la vista, pues Apel se preguntará por la forma en que se produce esta mediación de la libertad infinita y la universalidad de la pretensión moral de los individuos con un sistema de autoafirmación como el Estado, que es en esencia contingente y limitado ${ }^{23}$.

\section{Los límites de la eticidad de Hegel en la fundamentación de la ética discursiva de Karl-Otto Apel}

\section{1 Las Críticas de Apel al planteo hegeliano}

Apel señala que Hegel, para responder a la cuestión de la mediación de la libertad infinita con el Estado, sólo recurre a la guerra como momento que permite la superación del egoísmo de los intereses individuales, así como la formación de una solidaridad entre los individuos en la eticidad sustancial del Estado24. Apel menciona aquí

23 Ibíd., p. 84.

24 Loc. cit. 
que Hegel parece tener frente a sí el hecho de que la identificación, en el sentido de la solidaridad de los individuos con su comunidad, se produce cuando esta comunidad se enfrenta, en tanto sistema de autoafirmación, con otra comunidad concreta a la que se concibe como un sistema de autoafirmación enemigo ${ }^{25}$.

De todos modos, la pregunta relevante para Apel, más allá de cómo es posible fácticamente llegar a la unidad que se produce en la eticidad, es si, desde el punto de vista hegeliano, es posible obtener algún tipo de orientación para la acción. Es decir, si es posible reconstruir a partir de aquello que Hegel desarrolla en los Grundlinien der Philosophie des Rechts, y en concreto con el concepto de eticidad, algún tipo de parámetro normativo. De alguna manera la pregunta resulta retórica en la medida en que Apel conoce la empresa hegeliana y sabe que esta es una pregunta inadecuada al planteo, pues Hegel se propone explícitamente una superación de la dicotomía entre ser y deber ser. A consecuencia de ello, la única recomendación que puede obtener por parte de Hegel en este sentido-desarrollada bajo la figura del búho de Minerva- es que la filosofía siempre llega demasiado tarde si pretende decirle al mundo cómo debe $\operatorname{ser}^{26}$. De todas formas, la objeción fundamental de Apel al planteo hegeliano es precisamente cómo Hegel resuelve esta superación de la dicotomía entre ser y deber ser.

Apel sabe en efecto que la filosofía para Hegel es "su tiempo aprehendido en pensamientos ${ }^{\prime 27}$ y que por lo tanto ella no es más -ni menosque una "captación de lo real" y no un conjunto de orientaciones crítico-normativas para los hombres. De hecho, esto se encarga de dejarlo bien en claro el propio Hegel en el Prefacio a los Grundlinien der Philosophie des Rechts cuando menciona que su tratado

no debe ser otra cosa que el intento de concebir, y exponer el Estado como algo en sí mismo racional. En su carácter de

Ibíd., p. 85.

26 HEGEL, G. W. F. Grundlinien der Philosophie des Rechts, Akademie-Verlag, Berlin, 1981, p. 28.

27 lbíd., p. 27. 
escrito filosófico, nada más alejado de él que la pretensión de construir un Estado tal como debe ser. La enseñanza que puede radicar en él no consiste en enseñar al Estado como debe ser, sino enseñar cómo él, el universo ético, debe ser conocido (Vorrede, 27. Las cursivas son de Hegel).

De todas formas, la pregunta de Apel no parece del todo retórica, pues si bien Hegel se rehúsa a construir "un mundo tal como debe ser" su tratado no carece de una orientación práctica:

Reconocer la razón como la rosa en la cruz del presente y con ello gozar de éste, esta visión racional es la reconciliación con la realidad que concede la filosofía a aquellos que alguna vez han sentido la exigencia de concebir y al mismo tiempo conservar en lo sustancial la libertad subjetiva, y de no abandonarla en lo particular y contingente, sino llevarla a lo que es en sí y por sí (Vorrede, 27. Las cursivas son de Hegel).

Es decir, si bien Hegel concibe la tarea de la filosofía como una captación de lo real exclusivamente, busca con ello no obstante reconciliar a sus contemporáneos con su universo ético. De hecho, es así como ha sido interpretado por algunos autores el objetivo fundamental de los Grundlinien der Philosophie des Rechts ${ }^{28}$.

Ahora bien, esta manera que tiene Hegel de entender la función de la filosofía, a saber, "concebir lo que es", es incapaz para Apel de superar la mencionada dicotomía. Desde esta perspectiva, la mirada de la filosofía no es más que una comprensión "ex post factum" desde el punto de vista del presente histórico pero, como tal, esta comprensión de la realidad tiene el futuro fuera de $s^{i 29}$. En esto reside precisamente la aporía fundamental del planteo hegeliano, a saber, en el punto de

\footnotetext{
28 Aun más, Hardimon cree que este es el objetivo de toda la filosofía de Hegel. Cf. HARDIMON, M., "The Project of Reconciliation: Hegel's Social Philosophy", Philosophy and Public Affairs, vol. 21, № 2 (Spring, 1992), p. 166.

29 APEL, K.-O., Diskurs und Verantwortung, ed. cit., p. 87.
} 
vista "ex post factum" teórico especulativo que él adopta como un modo de superar los planteos modernos de tipo normativo, que en el caso de Hegel aparecen rebajados a la categoría de meros principios formales abstractos. El punto esencial aquí para Apel es que Hegel funde en un solo esfuerzo teórico dos instancias completamente diferentes entre sí. Hegel explícitamente confunde, por un lado, la captación reflexiva del mundo como historia y, por otro, la pregunta por el deber, que para Apel es siempre una pregunta referida al futuro. En última instancia, para Apel, la aporía del planteo hegeliano consiste en la "inutilidad del intento de superar con una filosofía teórica de tipo filosófico-histórica el planteamiento de la filosofía práctica" ${ }^{\prime 30}$. La historia del pensamiento parece haberle dado la razón en este punto a Apel, pues los intentos filosóficos posteriores también percibieron esta aporía e intentaron, a su manera, una mediación de la teoría con la praxis que para Apel también resulta insuficiente ${ }^{31}$.

La situación histórica posterior al planteo de Hegel ha significado una reapropiación de alguna de sus propuestas pero bajo condiciones diferentes. En esto ha tenido que ver significativamente el desarrollo de la hermenéutica que ha adoptado a su manera el problema que en Hegel se presentaba bajo la forma de la "captación de la realidad histórica". Pero más allá de ello, el panorama posterior en torno a la cuestión aquí tratada también se ha desarrollado en el sentido de la necesidad de mediar entre la pregunta por un principio normativo (formal y abstracto) y una reconstrucción conceptual de la realidad histórica, no solo de parte de aquellos que han procurado una superación en el sentido hegeliano de la dicotomía ser - deber ser, sino también de parte de aquellos que, retomando el planteo kantiano, han procurado desarrollar un principio normativo (formal y abstracto), pero más

\footnotetext{
$30 \quad$ Ibíd., p. 88.

31 Para una explicación extensa de por qué Apel considera que los desarrollos del marxismo, el existencialismo y el pragmatismo no han logrado una solución satisfactoria a este problema, cf. 1988: 89-91. Véase también del mismo autor "Reflexion und materielle Praxis: Zur erkenntnisanthropologischen Begründung der Dialektik zwischen Hegel und Marx" en: Id.:Transformation der Philosophie, Suhrkamp, Frankfurt a. M., 1973, Bd. 2.: pp. 9-27.
} 
atento al conjunto de las configuraciones históricas en las cuales aquel principio debe ser realizado. Si la situación post hegeliana ha remitido nuevamente la pregunta por el deber ser a los planteos de Kant ${ }^{32}$, este retorno se ha dado con la conciencia de la necesidad de incluir una reconstrucción teórica de la realidad histórica al modo hegeliano. Esta es ni más ni menos que la situación éticamente relevante que se presenta luego de lo que Apel llama la reducción hermenéutica del hegelianismo ${ }^{33}$, es decir, conjugar la exigencia de un principio normativo universal en la senda de los planteos de Kant y una comprensión "ex post factum" de la realidad histórica al modo hegeliano.

\section{2 El Lugar de la Eticidad de Hegel en la Fundamentación de la Ética discursiva de Karl-Otto Apel}

Dentro de la situación que Apel percibe como éticamente relevante, la fundamentación que emprende de la ética tiene como punto de partida algunos motivos indudablemente hegelianos: primero, la superación del dualismo metafísico kantiano y, segundo, el descubrimiento de la realidad histórica de las normas y de las instituciones. Como ha quedado claro, Apel no toma como tal el planteo hegeliano, al que explícitamente critica, sino lo que llama la reducción hermenéutica de su propuesta efectuada por el devenir histórico del pensamiento posterior. Es decir, el punto de partida de su esfuerzo de una fundamentación de la ética se ubica, por un lado, entre la necesidad de tener en cuenta aquello que Hegel conceptualiza con la idea de "eticidad", pero de la que no puede extraerse ninguna orientación normativa hacia el futuro. Por otro lado, Apel también hace hincapié en la necesidad de sostener un planteamiento normativo de la praxis como puede encontrarse en los planteos prácticos de Kant, pero atento a la configuración histórica de las tradiciones, las normas y las instituciones existentes, atención que no tenía lugar en el esquema práctico de este último.

32 APEL, K.-O., Diskurs und Verantwortung, ed. cit., p. 91.

33 Ibíd., p. 92. 
La fundamentación apeliana de la ética, que aquí solo puedo esquematizar en sus rasgos generales para rastrear cómo en ella se tienen en cuenta los planteos de Hegel, ha sido pensada desde un principio como la transformación postmetafísica de la filosofía kantiana en general y de sus aspectos prácticos en particular ${ }^{34}$. Por lo tanto, Apel ha pensado su propuesta desde un principio como una continuación de los planteos de Kant y, de hecho, toda la ética apeliana lleva en su estructuración las huellas fundamentales del esquema kantiano: su intento de una fundamentación última a priori a partir de la razón, su universalismo irrenunciable y, por lo tanto, también su formalismo, entre otros rasgos esenciales. De aquí resulta especialmente el interés que puede tener rastrear los elementos que Apel toma de Hegel a pesar de las intenciones explícitas de su autor por presentarse como continuador de una determinada tradición de pensamiento que se encuentra distanciada en cuanto a la forma de comprender la praxis de los hombres.

El planteo básico de la ética apeliana tal como ha sido desarrollado en un artículo programático de 1973, denominado Das Apriori der Kommunikationsgemeinschaft und die Grundlagen der Ethik y que se ha mantenido inalterable hasta nuestros días, consiste en extraer sus principios normativos de la práctica argumentativa cotidiana de los hombres. Para Apel en todo momento en que argumentamos hacemos presuposiciones de tipo normativo que hacen posible la propia argumentación y, en este sentido, se las concibe a estas presuposiciones como condiciones de posibilidad de la argumentación. Así la pregunta kantiana por las condiciones de posibilidad de la experiencia -y de los objetos de la experiencia- aparece reemplazada en esta transformación postmetafísica por las condiciones de posibilidad de la argumentación seria y con sentido ${ }^{35}$. Con esta transformación, el planteo apeliano

34 APEL, K.-O., Transformation der Philosophie, Suhrkamp, Frankfurt a. M., Suhrkamp, Bd. II, p. 358-436 e Id., Teoría de la Verdad y Ética del Discurso, Paidós, Barcelona, 1995, p. 151.

35 Id., Diskurs und Verantwortung, ed. cit., p. 97; Kuhlmann, W., "Transzendentalphilosophie nach dem linguistic turn", ed. cit., p. 22 y "Was spricht heute für eine Philosophie des kantischen Typs?", ed. cit., p. 66. 
da cuenta de manera clara del giro lingüístico experimentado por la filosofía del siglo $X X^{36}$. Aun más, puede decirse que esta es la brecha más importante que separa el planteo clásico de la filosofía trascendental y el planteo pragmático trascendental de Apel. Pero ya en este cambio de paradigma quedan incluidas las aportaciones hegelianas, al menos en la forma que adoptó posteriormente su planteo, en el sentido de una reducción hermenéutica de su desarrollo. Pues para Apel, la filosofía trascendental que resulta de la transformación de la filosofía tradicional kantiana tiene el status de una semiótica trascendental que contiene como tal una pragmática trascendental del lenguaje y una hermenéutica trascendental, que funciona a modo de fundamento de las "ciencias del espíritu" ${ }^{37}$.

El punto fundamental para el desarrollo apeliano de una ética es la idea de que algunas de las condiciones de posibilidad de la argumentación, condiciones que no pueden ser negadas sin cometer lo que Apel denomina una autocontradicción performativa, son condiciones normati$v s^{38}$. Este punto es de importancia radical para todo el esquema, pues en esta instancia se aúnan la dimensión teórica y la dimensión práctica de la razón, las cuales, en Kant, si bien él señalaba que se trataban de dos dimensiones de la misma razón ${ }^{39}$ éstas aparecían separadas y en clara inconsistencia la una con la otra ${ }^{40}$. Es decir, en el esquema de la pragmática trascendental del lenguaje de Apel se produce la unidad de la razón teórica con la razón práctica, que como unidad de teoría y praxis preocupaba especialmente a Hegel.

Es imprescindible mencionar que en esta transformación posmetafísica se da solución al déficit de fundamentación que aquejaba a la ética de Kant. Este déficit se producía, brevemente, pues para Kant era impo-

36 KUHLMANN, W., "Was spricht heute für eine Philosophie des kantischen Typs?", ed. cit., p. 75.

37 APEL, K.-O., Diskurs und Verantwortung, ed. cit., p. 96.

38 Ibíd., p. 97.

39 KANT, I., Kritik der reinen Vernunft, ed. cit., p. 391.

40 KUHLMANN, W., "Solipsismus in Kants Praktische Philosophie", ed. cit., pp. 268-270. 
sible de demostrar la cognoscibilidad de la libertad y éste terminaba por remitirla a un "factum de la razón"; este último es reinterpretado ahora ni más ni menos que bajo la forma del nuevo principio de la ética apeliana. Es decir, "el factum de la razón" pasa a ser el principio fundamental de la ética necesariamente reconocido por aquellos que se embarcan en una discusión argumentativa como forma de solucionar conflictos o dirimir la legitimidad de las normas ${ }^{41}$. Dicho principio, también conocido como "metanorma", tiene como contenido precisamente la exigencia de una resolución argumentativa de todos los conflictos a través de discursos prácticos. Pero también es fundamental señalar que aquí no quedan incluidos solo los aspectos mencionados de Kant sino que puede reinterpretarse o considerarse como incluida para Apel otra exigencia, esta vez proveniente del planteo hegeliano. Para Apel debe incluirse entre las condiciones normativas de posibilidad de la argumentación y del pensamiento aquello que Hegel desarrollaba con la figura del Señor y el Siervo ${ }^{42}$, es decir, la mediación y el logro de la autoconciencia a través del reconocimiento de los otros ${ }^{43}$. En este sentido, es posible para Apel reinterpretar la metanorma de la ética del discurso, como una norma básica de la reciprocidad universalizad $a^{44}$. Es decir, está presupuesto en el discurso argumentativo como una condición de posibilidad normativa el reconocimiento de todos los participantes en la argumentación como personas libres, racionales y con iguales derechos. Pero las referencias a Hegel no terminan aquí sino que para Apel es aun posible, mediante la transformación de la filosofía trascendental que él propone, superar aquello que también preocupaba a Hegel, a saber, el dualismo entre la autonomía de la conciencia y la realidad social ${ }^{45}$.

APEL, K.-O., Diskurs und Verantwortung, ed. cit., p. 99.

42 HEGEL, G. W. F., Fenomenología del espíritu, FCE, México, 1985, pp. $117-120$.

43 APEL, K.-O., Diskurs und Verantwortung, ed. cit., p. 99.

44 APEL, K.-O., "Ist die Philosophische Letzbegründung moralischer Normen auf die reale Praxis anwendbar?", ed. cit., pp. 618 y 619 e Id., Diskurs und Verantwortung, ed. cit., p. 99.

45 APEL, K.-O., Diskurs und Verantwortung, ed. cit., p. 100. 
A esto puede agregarse un elemento más al que Apel considera que puede darse lugar dentro de su fundamentación de la ética. Una de las principales críticas que Hegel dirigió contra Kant consistía en señalar, como ya se mencionó, que no es posible deducir de su imperativo categórico, entendido éste como criterio que señala la no contracción de las leyes universales, la validez de ninguna institución. Precisamente lo que necesita ser evaluado normativamente es aquello que el imperativo categórico presupone, es decir, las circunstancias sociales, las prácticas, los fines, las instituciones y que, por lo tanto, el imperativo categórico no puede ser el principio normativo fundamental (§ 135). Si bien se ha señalado que esta lectura del imperativo categórico por parte de Hegel parece descansar en una serie de errores ${ }^{46}$ o que incluso esta no es la forma en que Hegel lo interpreta realmente ${ }^{47}$, Apel cree que su ética fundamentada en dos niveles puede dar solución a esta objeción ${ }^{48}$.

Los dos niveles a los que Apel se refiere surgen cuando la fundamentación pragmático-trascendental del principio del discurso debe enfrentar el problema de la fundamentación o legitimidad de las normas en la realidad concreta. Aquí es donde Apel ha distinguido entonces entre un primer nivel en la ética del discurso, encargado de la fundamentación de la "metanorma", y un segundo nivel encargado de la fundamentación de las normas situacionales concretas a través de los discursos prácticos, en los que intervienen todos los posibles afectados (o sus representantes) por la implementación de esas normas ${ }^{49}$. Con esta división cree Apel poder dar solución a aquella dificultad que se producía en Kant cuando éste debía enfrentar la aplicación del imperativo categórico a situaciones concretas y por la cual solo podía concebir la generación de normas y deberes concre-

\footnotetext{
46 WESTPHAL, K., op. cit., p. 252.

47 LOTTENBACH, H. "Hegel's Critique of Kant in the Philosophy of Right". Kant-Studien 86:2 (1995): 211-230.

48 APEL, K.-O., "Ist die Philosophische Letzbegründung moralischer Normen auf die reale Praxis anwendbar?", ed. cit., p. 621.

49 APEL, K.-O., Diskurs und Verantwortung, ed. cit., p. 134.
} 
tos únicamente en la forma de la deducción a partir del imperativo categórico. En el paradigma apeliano, las normas situacionales de la moral y el derecho no se deducen directamente de la metanorma (el principio del discurso) sino que se generan en los discursos prácticos en los que intervienen todos los posibles afectados por la puesta en práctica de esa norma. Es de esta manera, entonces, como Apel cree ver solucionado el problema referido al contenido de las normas que el imperativo categórico, según Hegel, era incapaz de generar por sí solo. Así también, el procedimiento de dos niveles de fundamentación de normas apeliano no solo puede sino que debe legitimar las normas situacionales concretas ${ }^{50}$.

De todas formas, por más que Apel se encargue de destacar aquellos aspectos del planteo de Hegel que es posible incluir dentro de su propuesta de fundamentación ética, y de la filosofía trascendental transformada que le sirve de trasfondo teórico, una brecha fundamental separa al programa hegeliano del apeliano y es precisamente un dualismo que se traslada desde el esquema kantiano al proyecto de Apel y que éste cree necesariamente que debe ser mantenido. Este dualismo aparece en Apel en la idea central de que en toda argumentación real se anticipa contrafácticamente una comunidad ideal de argumentación, en la cual los conflictos se resuelven siempre argumentativamente $y$, por lo tanto, es posible hablar aquí de dos planos que pueden asimilarse a dos planos que Hegel se propuso deliberadamente "superar" es decir, el plano del ser (Sein) y el plano del deber ser (Sollen). Concretamente, así como existe una comunidad real de comunicación que debe entendérsela como el conjunto de los condicionamientos fácticos en los que se encuentran los argumentantes a la hora de $\operatorname{argumentar}^{51}$, existe siempre, inevitablemente presupuesta, una comunidad ideal de comunicación anticipada contrafácticamente y concebida como un conjunto de condiciones ideales que hacen posible la argumenta-

50 APEL, K.-O., "Ist die Philosophische Letzbegründung moralischer Normen auf die reale Praxis anwendbar?", ed. cit., p. 622.

51 APEL, K.-O., Teoría de la Verdad y Ética del Discurso, ed. cit., p. 158. 
ción. Para Apel es necesario mantener estas dos dimensiones si no se quiere correr el riesgo de "absolutizar" las instituciones como parece suceder en el esquema hegeliano de la eticidad sustancial ${ }^{52}$. Aquí la exigencia de una resolución discursiva de los conflictos o una legitimación discursiva de las normas, exigencia que expresa el contenido de la metanorma presupuesta entre las condiciones normativas de la argumentación, no encuentra nunca su realización plena en la realidad y permanece siempre como un ideal regulativo que debe ser tenido en cuenta en todas las acciones de los hombres. En este sentido, como dice Apel, "nunca viviremos en un mundo en el cual la total mediación de ser y deber ser -en el sentido de Hegel: la reconciliación de la Idea consigo misma- sea realidad. ${ }^{153}$

De todas formas, aquí Apel "supera" a Hegel pero a la manera hegeliana, es decir, conteniéndolo, pues la idea de una anticipación contrafáctica de condiciones ideales de argumentación puede compararse a la anticipación especulativa de una realización de lo racional central al punto de vista de la filosofía hegeliana ${ }^{54}$. Ahora bien, así como la fundamentación apeliana puede incluir a Hegel en una perspectiva a futuro, así también lo incluye en una necesaria remisión e interpretación del pasado. Esto claramente lo hace en la forma en que el pensamiento posterior adoptó la perspectiva hegeliana, es decir, en la forma de una hermenéutica histórica, en la forma de un pasado que constituye de una manera permanente nuestro presente.

Aquí la metanorma de la ética del discurso hace referencia, como su contenido esencial, a un acuerdo o entendimiento que debe ser alcanzado, pero en este caso sobre el contenido de la historia misma y, en el caso ético-político, al contenido de las instituciones o tradiciones que avalan o consagran ciertas prácticas. Esta referencia es importante, pues de alguna manera para Apel esta circunstancia es imprescindible para darle un contenido a los discursos prácticos sobre fundamentación

\footnotetext{
52 APEL, K.-O., Diskurs und Verantwortung, ed. cit., p. 100.

53 Ibíd., p. 101.

54 Ibíd., p. 100.
} 
y legitimación de normas ${ }^{55}$ y que ellos no permanezcan "formales y abstractos" como el imperativo categórico. Pero también es elemental, o tal vez esencial, al problema aquí tratado, y que pone en veredas diferentes a los planteos de Apel y de Hegel, es que en ninguna circunstancia la dimensión normativa debe ser remitida exclusivamente a una práctica tradicional o histórica determinada, sino que debe existir siempre una mediación crítica entre estas tradiciones y la metanorma del discurso que necesariamente, como ya se ha visto, está referida contrafácticamente a un futuro y a cuya realización en la práctica no es posible renunciar.

\section{Algunas conclusiones}

Si bien la fundamentación de la ética que Apel desarrolla está claramente enmarcada dentro la forma kantiana de pensar el ámbito normativo de lo práctico, toda su propuesta en este respecto puede ser pensada como un gran intento de mediar dos grandes figuras dentro de la tradición del pensamiento y más concretamente dos intentos paradigmáticamente diferentes de resolver la relación entre teoría y praxis. Aquí en esencia para Apel la mediación siempre crítica de su propuesta se produce, por un lado, entre la ética de Kant -en verdad, toda su filosofía práctica y teórica- y, por otro, la filosofía de Hegel. Ha sido este último quien con sus críticas puso de relieve los límites del planteo kantiano y la necesidad de tener en cuenta todo un conjunto de fenómenos histórico-espirituales comprendidos bajo la rúbrica del espíritu objetivo y en concreto los abarcados por la llamada eticidad (Sittlichkeit).

Sin embargo, el problema de la normatividad del ámbito de lo práctico para Apel no se resuelve como Hegel pensaba, mostrando o haciendo comprender a sus contemporáneos cómo lo racional se encontraba detrás de las configuraciones de la sociedad moderna, es decir, como un intento especulativo-teórico de "captar la realidad

55 lbíd., p. 102. 
ética" constituida históricamente. Este intento resulta para Apel una forma de disolver la mediación de teoría y praxis, dimensión que está necesariamente presupuesta en el uso cotidiano del lenguaje. El uso del lenguaje contiene en sí dos dimensiones que no pueden ser abolidas sin abolir el lenguaje mismo. En el uso ordinario de la argumentación nuestras palabras remiten a una comunidad histórica concreta y determinada de la cual nuestras palabras obtienen toda su fuerza y riqueza de connotaciones semánticas y en las cuales puede verse por detrás toda una historia que las constituye. Sin embargo, también, para que toda argumentación pueda llevar a cabo aquello para lo que se la emplea debe necesariamente tenerse en cuenta aquello que ella inevitablemente presupone, es decir, un conjunto de condiciones de posibilidad que son a la vez constitutivas y normativas en un sentido práctico. Es decir, siempre que usamos el lenguaje con un sentido argumentativo presuponemos una comunidad ideal de argumentación que se presenta contrafácticamente anticipada, es decir, con una referencia inevitable hacia el futuro.

Por último, puede verse cómo se perfila aquí otra forma totalmente diferente de mediar la teoría y la praxis. No estamos ya bajo la forma kantiana de abordar esta relación, pero tampoco bajo la forma hegeliana de disolverla o "superarla". Las anteriores formas de abordar esta relación se hacían a costa de alguna de las dos instancias a relacionar. En el caso de Kant, a favor de la teoría, pues bajo la forma de una exclusiva preocupación por la fundamentación, descuidaba su momento de praxis, de aplicación. En el caso de Hegel, a favor de la praxis al punto de condenar cualquier indicación normativa por parte de la teoría. Para la ética del discurso, dicha relación está ya implícita en el lenguaje argumentativo como una tensión ineliminable. De esta manera, la transformación pragmático-lingüística de la ética de Kant, no solo pone fin a las aporías del planteo kantiano que ella misma ha detectado, sino que también supera aquellas inconsistencias señaladas en su momento por las agudas críticas de Hegel. Sin embargo, a pesar de mostrar en su desarrollo algunas adquisiciones propias de la propuesta hegeliana (sobre todo la consideración insoslayable de la 
realidad histórica de las tradiciones e instituciones existentes), la ética del discurso muestra la imposibilidad de desarrollar un programa práctico normativo a partir de las propias premisas del planteo hegeliano y retiene en su estructura las líneas fundamentales que definen a la propuesta kantiana, de la cual, en última instancia, se reclama como legítima heredera.

\section{Bibliografía}

APEL, Karl-Otto. "Reflexion und materielle Praxis: Zur erkenntnisanthropologischen Begründung der Dialektik zwischen Hegel und Marx" en Id. Transformation der Philosophie, Frankfurt a. M.: Suhrkamp, Bd. 2, 1973.

APEL, Karl-Otto. "Ist die Philosophische Letzbegründung moralischer Normen auf die reale Praxis anwendbar?" en Apel, K.-O., Böhler, D. und Rebel, K. (Hrgs.). Studientexte 2 Funkkolleg Praktische Philosophie / Ethik.Weinheim und Basel: Beltz, 1984.

APEL, Karl-Otto. Diskurs und Verantwortung. Das Problem des Übergangs zur postkonventionellen Moral. Frankfurt: Suhrkamp, 1988.

APEL, Karl-Otto. Teoría de la Verdad y Ética del Discurso. Barcelona: Paidós, 1995.

APEL, Karl-Otto \& Pozzo, Ricardo. Zur Rekonstruktion der praktischen Philosophie. Stuttgart-Bad Canstatt: Froomann-Holzboog, 1990.

BEISER, Frederick (ed.). The Cambridge Companion to Hegel. Cambridge: Cambridge University Press, 1993.

BÖHLER, Dietrich. Rekonstruktive Pragmatik. Von der Bewußtseinsphilosophie zur Kommunikationsreflexion: Neubegründung der praktischen Wissenschaften und Philosophie. Frankfurt a.M: Suhrkamp, 1985.

GIUSTI, Miguel. "Autonomía y Reconocimiento". Ideas y Valores 133 (Abril de 2007): 39-56.

HABERMAS, Jürgen. "Treffen Hegels Einwände gegen Kant auch auf die Diskursethik zu?" en Id. Erläuterungen zur Diskursethik. Frankfurt a. M.: Suhrkamp, 1991.

HARDIMON, Michael. "The Project of Reconciliation: Hegel's Social Philosophy". Philosophy and Public Affairs. 212 (Spring 1992): 165-195.

HEGEL, G. W. F. Grundlinien der Philosophie des Rechts. Berlin: AkademieVerlag, 1981. 
HEGEL, G. W. F. Fenomenología del espíritu. México: FCE, 1985.

HENRICH, Dieter (Hrsg.). Kant oder Hegel?: Über Formen der Begründung in der Philosophie. Stuttgart: Klett-Cotta, 1983.

KANT, Immanuel. Kants gesammelte Schriften. Berlin: Akademie-Textausgabe, De Gruyter, 1968.

KUHLMANN, Wolfgang. "Solipsismus in Kants Praktische Philosophie" en Apel, K.-O. \& Pozzo, R. Zur Rekonstruktion der praktischen Philosophie, Stuttgart-Bad Canstatt: Froomann-Holzboog, 1990.

KUHLMANN, Wolfgang. "Transzendentalphilosophie nach dem linguistic turn" en Id. Kant und die Transzendentalpragamtik. Würzburg: Königshausen \& Neumann, 1992.

KUHLMANN, Wolfgang. "Was spricht heute für eine Philosophie des kantischen Typs?" en Id. Kant und die Transzendentalpragamtik. Würzburg: Königshausen \& Neumann, 1992b.

LOTTENBACH, H. "Hegel's Critique of Kant in the Philosophy of Right". Kant-Studien 86:2 (1995): 211-230.

WESTPHAL, Kenneth. "The basic context and structure of Hegel's Philosophy of Right" en Beiser, F. (ed.). The Cambridge Companion to Hegel. Cambridge: Cambridge University Press, 1993.

WOOD, Allen. "Hegel's ethics" en Beiser, F. (ed.). The Cambridge Companion to Hegel. Cambridge: Cambridge University Press, 1993. 